(Aus der Chir. Univ.-Klinik Berlin. Geheimrat A. Bier.)

\title{
U̇ber Spalt- und Höhlenbildung. Primäre Hohlraumbildung oder Gewebsverflüssigung?
}

\author{
Von
}

\author{
Dr. B. Martin. \\ Assistent der Klinik.
}

Mit 3 Abbildungenauf Tafel II.

Die erworbenen Spaltbildungen, Schleimbeutel, Hygrome und Ganglien hat man schon frühzeitig als eng verwandte Gebilde erkannt. Sie sind deshalb auch häufig von gemeinsamen Gesichtspunkten aus betrachtet worden. Für die Art ihrer Entstehung, den formativen Bildungsvorgang, war rückschließend wohl die Erkenntnis maßgebend, daß die tiefen Schleimbeutel und Gelenke häufig miteinander im $\mathrm{Zu}$ sammenhang stehen und histologisch weitgehend übereinstimmen. Das gab Veranlassung, das bei den Gelenken wirksame genetische Moment auch auf die Schleimbeutel anzuwenden, so daß schließlich für die Schleimbeutel und Ganglien die Auffassung vorherrschend wurde, daß sie durch Verflüssigung oder Einschmelzung des Bindegewebes entstanden seien.

Die Beschreibung des interstitiellen Bindegewebes als ein wenig fest durchwachsenes Spaltsystem, in welchem sich, besonders unter der Haut, ,individuell und während des Lebens UUbergänge von Gewebsmaschen bis zu Schleimbeuteln vorfinden" (Henke), läßt aber die Genese der in Frage kommenden Bildungen noch in anderer Weise denkbar erscheinen. Virchow hat diese anatomischen Verhältnisse zweifellos zur Beurteilung mit herangezogen, wenn er schreibt, „daß durch einen Akt der Atrophierung Lücken gebildet werden, und daß die Anhäufung von Flüssigkeit dem Vorhandensein einer Cavität folgt. Diese kann eine neugebildete sein, kurz bevor die Ausscheidung geschieht". Die Ausscheidung würde aus dem Spaltsystem zu erfolgen haben, und die Höhle könnte sowohl durch Atrophie der Balken und Faserzüge als auch durch Zusammenfließen kleiner Spalten entstanden gedacht werden.

Dieser Vorgang wäre in Parallele zu setzen mit der Entstehung der subcutanen Lymphergüsse und der Cystenbildung nach Blutergüssen: Auch hierbei bildet sich eine Höhle im Gewebe, in die sich eine Flüssigkeit ergießt. Nur spielt nicht eine Atrophie der Bindegewebsteile eine 
Rolle, sondern die Höhlenbildung geschieht traumatisch durch Auseinanderzerren und Zerreißen des Gewebes. Es spricht für die Verwandtschaft aller der genannten erworbenen Spalt- und Höhlenbildungen, daß ihre Wandung durchgehend dieselbe histologische Struktur aufweist. Deshalb halten wir es für erlaubt, auch die traumatischen lymphatischen- und Blutergüsse zusammen mit den erworbenen Schleimbeuteln, Hygromen und Ganglien in bezug auf ihre Entstehungsweise zu untersuchen.

Über die Schleimbeutel hat lange der Streit bestanden, ob man sie als Höhlen mit oder ohne Epithel bzw. Endothel aufzufassen habe. Durch die Arbeiten von H. Braun und Hammar wurde die Frage dahin entschieden, daß weder die Gelenke noch Schleimbeutel mit einer dieser Zellarten bekleidet seien, sondern $\mathrm{da} \beta$ wir es mit differenzierten Bindegewebszellen zu tun haben. Diese Auffassung trifft jedoch nur für einen Teil der Schleimbeutel zu, wie es von Heinecke in einer Abhandlung über die Anatomie und Pathologie der Schleimbeutel und Sehnenscheiden beschrieben wird. Es ist dabei für unsere Untersuchungen unwesentlich, daß Heinecke noch von der irrtümlichen Auffassung ausgeht, die Schleimbeutel seien zum Teil mit Epithel ausgekleidet. Heinecke macht einen Unterschied zwischen den später erworbenen und den angelegten Schleimbeuteln und findet neben Schleimbeuteln mit einer epithelbekleideten Membran solche ohne Epithel mit Membran und solche auch selbst ohne Membran, deren Innenfläche nicht glatt, sondern unregelmäßig erscheint. Namentlich die membranlosen Schleimbeutel ohne Zellauskleidung gehören dem Unterhautzellgewebe an und entstehen bei älteren Individuen durch Auseinanderzerren der Bindegewebsmaschen. Heinecke nennt sie unfertige Schleimbeutel. Als Beispiel eines solchen sei kurz eine Bursa praepatellaris beschrieken, die im frühen Kindesalter noch gänzlich fehlt und erst später gebildet wird.

Beobachtung 1. Normale Bursa praepatellaris von der Leiche eines erwachsenen Mannes. (Härtung in Formalin, Paraffineinbettung, Färbung nach จ. Gieson.)

Die Oberfläche des Schleimbeutels wird auf beiden Seiten von einem leuchtend rot gefärbten, gefäßarmen Bindegewebsstreifen begrenzt. Auf der einen Seite ist dieser breiter als auf der anderen. Die Bindegewebsfasern dicht unter der Oberfläche erscheinen gequollen, die Zellen sind mäßig zahlreich und haben bis dicht unter die Grenzschicht eine schöne, schlanke Gestalt. Diese Bindegewebslage geht nach der Höhle zu rasch in eine sehr bald farblos werdende Zone über, in welcher man verdickte, glasige Bindegewebsfaserreste und sehr stark aufgeblasene, ganz blaß gefärbte Bindegewebskerne sieht, die die Größe der ursprünglichen um ein Bedeutendes überschreiten und länglich-ovale bis unregelmäßige, mit Einschnürungen versehene Figur besitzen. Die Bindegewebsfasern verlieren sich stellenweis unter büschelförmiger Auflösung ihres Zusammenhanges und unter Einbüßen ihrer Färbbarkeit in diese farblose Zone hinein, wie wenn sie einer allmählichen Auflösung entgegengingen. Bei stärkster Vergrößerung sieht 
man dän an solchen Stellen außerordentlich große, ganz blasse, zart gekörnte Zellkerne.

Eine Begrenzung der Oberfläche durch eine Anhäufung von Zellen, wie bei der Membrana synovialis, oder irgendein anderer Abschluß des Gewebes durch eine deckende Zellschicht ist nirgends auch nur angedeutet.

Wir haben es mit einem Schleimbeutel zu tun, dessen Innenrand weder eine besondere Grenzmembran noch eine deckende Zellschicht besitzt, sondern dessen Wand zutreffend als nacktes Bindegewebe bezeichnet wurde. Der dem subcutanen Bindegewebe angehörende erworbene Schleimbeutel hat also keineswegs eine dreigeschichtete Wand, wie das auch neuerdings noch vielfach angegeben wird, sondern das Bindegewebe ist dort, wo das ,Endothel", d. h. eine Lage polygonaler Bindegewebszellen, fehlt, derb und reich an rundlichen, den Knorpelzellen ähnlichen Elementen (Stöhr). Von diesen nackten, unfertigen Schleimbeuteln bestehen Übergänge bis zur Struktur der. Membrana synovialis der Gelenke, welche neuerdings von $\mathrm{Lubosch}$ als ein seinen mechanischen Aufgaben angepaßtes Knorpelgewebe aufgefaßt wird. Diese Ansicht begegnet sich mit der eben angeführten Stöhrs. Auch uns fielen solche Anklänge auf.

Bei der Betrachtung der Schleimbeutelwand mub es auffallen, daß die sich gegenüberliegenden Wände nicht verkleben und verwachsen. Wir sehen eine farblose Masse auf der Innenfläche liegen', die, gekörnt und strukturlos, große, blasige, ganz blaß gefärbte Kerne in sich birgt, und in welche Bindegewebsbüschel hineinragen, die rasch thre Färbbarkeit verlieren und offenbar einer Einschmelzung entgegengehen. Dieser Prozeß deutet auf eine Auflösung der oberflächlichsten Gewebsschicht durch die in dem Schleimbeutel enthaltene Flüssigkeit, in der, da die Schleimbeutel enge Verwandte der Gelenke sind, Synovia angenommen werden muß. Frerichs hat zuerst festgestellt, daß die Synovia zum Teil aus aufgelösten Gewebsbestandteilen besteht. So finden wir auch eine Erklärung, warum die sich so nahe gegenüberliegenden Wände des Schleimbeutels nicht verkleben. Der flüssige Inhalt erhält den Spalt.

Die Schleimbeutel sind wir gewohnt als normale Bildungen anzusehen, 'trotzdem ein Teil von ihnen erst später erworben ist. Sie können erkranken und zu einer großen Flüssigkeitsansammlung führen: dem Hygrom. Das Hygrom ist ein im Reizzustand befindlicher Schleimbeutel. Als Beispiel diene folgende kurze Beschreibung.

Beobachtung 2. Hygroma bursae olecrani eines erwachsenen Mädchens. Behandlung des Präparates wie bei Beobachtung 1.

Die Wand wird vornehmlich aus zwei Schichten gebildet. Die äußere besteht aus einem mehr oder weniger lockeren, gefäßreichen Bindegewebe mit großen, eingelagerten Fettgewebspartien. Die innere Schicht; welche der Oberfläche anliegt, ist gegen die äußere scharf abgegrenzt. Sie ist kernreich und ihr Zwischengewebe färbt sich blaßrot. Die Fibrillenbildung ist hier in der Tiefe fortgeschritte- 
ner als an der Oberfläche. Die Oberfläche ist unregelmäßig, mit breiten Vorsprüngen versehen. Die innerste Zone dieser Auskleidung enthält nur an ein. zelnen Stellen eine geringe Menge junger Blutgefäßße. An einzelnen Stellen findet man in ihr, durch die Breite der inneren Wandschicht verstreut, gelbgefärbte, hyaline Flecke und Streifen, gestreckt und geschlängelt, auch ganz schmale, fädige, in denen, soweit sie breit genug sind, wohlgefärbte Bindegewebskerne liegen. Dicht an der Oberfläche sind die jungen Bindegewebszellen stellenweis zu einem schmalen Saum, stellenweis zu einem breiten Band dicht aneinander gelagert. Sie sind größer, als in der Tiefe und haben sehr mannigfaltige Gestalt. Die Oberfläche schließlich ist bei starker Vergrößerung an einzelnen Stellen glatt, begrenzt von einem Saum der eben erwähnten Zellen; an anderen Stellen liegt einem solchen noch eine rot gefärbte Schicht auf; an anderen wiederum sieht man, wie das Gewebe ohne bestimmte Grenze, unter Auflockerung der Zwischensubstanz, in die freie Höhle aufgeht. Einer der plumpen, kurzen Vorsprünge enthält einen Kern aus älterem, leuchtend rot gefärbtem Bindegewebe mit zahlreichen kleinen GefäBquerschnitten. Frei im Lumen befindet sich ein ovaler Gewebsquerschnitt, der ebenfalls in der Mitte altes Bindegewebe mit zahlreichen Gefäßdurchschnitten enthält und von einem allseitig scharf abgrenzbaren Mantel umgeben ist. In diesem Mantel sind wiederum zwei Zonen zu unterseheiden: die innere, dem Kern zugewandte, ist locker und enthält feine Bindegewebsfibrillen in netzförmiger Anordnung. In ihr eingelagert sind zahlreiche, noch junge Bindegewebszellen. Im vorliegenden Präparat befindet sich nur ein Gefäßquerschnitt in dieser Zone, sonst keine. Die äußere, die Oberfläche bildende Zone ist wiederum dichter, intensiver rot gefärbt, mit klarer fibrillärer Struktur und Bindegewebszellen derselben Form, wie die innere Zone. Außen auf diesem dichten Bindegewebe liegt eine mehr oder weniger dicke Lage, die einen gelblich-roten bis braungelben Farbenton angenommen hat, je nachdem das Bindegewebe oder eine hyaline Masse überwiegt. Hier liegen in den gelbbraunen Partien schön ausgeprägte Fibroblasten, die Oberfläche ist unregelmäßig ausgefasert, das Gewebe geht ohne $\mathrm{Ab}$. grenzung in den Hygrominhalt iuber. An den mehr rötlich aussehenden Stellen ist bereits die Ausbildung der Bindegewebsfibrillen deutlich zu erkennen. Die Zellen sind schmaler und schlanker geworden und nähern sich der Form der fixen Bindegewebszellen. Besonders ist die Bildung von rotgefärbten Bindegewebsfibrillen als Abschluß gegen die Höhle zu vermerken.

Wir finden an diesem Präparat erhebliche Verschiedenheiten gegenüber dem der ersten Beobachtung. Die innerste Lage hat die Zeichen jungen Granulationsgewebes mit zahlreichen Fibroblasten und spärlichen, jungen Blutgefäßen. Das Zwischengewebe ist in den obersten, jüngsten Partien noch strukturlos and ohne Bindegewebsfibrillen. Darin eingelagert sind homogene, zum Teil körnige Niederschlagsreste vorhanden, welche, wie später noch zu beweisen sein wird, der Flüssigkeit im Innern des Hygroms entstammen. An der Oberfläche hat sich ein mehr oder weniger breiter Saum großer, vielgestaltiger Fibroblasten gebildet. An anderen Stellen aber ist die Oberfläche ohne Zellbesatz und ähnelt der des oben beschriebenen, normalen Schleimbeutels. Die zottenförmigen Gebilde und der frei im Lumen liegende Gewebsquerschnitt enthalten im Innern altes Bindegewebe mit wohl ausgebildeten Gefäßen, welches umringt wird von jungem Granulationsgewebe von derselben Beschaffenheit wie das an der Wand des Hygroms. Es handelt 
sich also um stehengebliebene Bindegewebsstränge, welche durch Organisation eines Niederschlages an Stärke zugenommen haben.

Wenn'wir aus diesen beiden Befunden am normalen und pathologisch veränderten Schleimbeutel einen Schluß ziehen, so erweist sich das vorliegende Hygrom der allgemein geltenden Anschauung entsprechend als ein Schleimbeutel im Reizzustande. Das Hygrom verdankt seine Entstehung einer durch Reizwirkung hervorgerufenen verstärkten Flüssigkeitsansammlung im bereits bestehenden Cavum des Schleimbeutels. Aus diesem Erguß scheidet sich auf der Wand ein Niederschlag $a b$, der gelb gefärbt ist und von der Wand aus organisiert wird.

Die Analogie der Ganglien mit den Schleimbeuteln und Hygromen ist mehrfach in der Literatur betont und begründet worden. Virchow, Lange mak und Sumita haben diese Anschauung klar ausgesprochen, und Virchow beurteilt diese, hygromatösen und hydrocelenartigen Bildungen " von einem gemeinschaftlichen Gesichtspunkt. Trotz der mannigfaltigen und scheinbar abschließenden Untersuchungen über den ersten Entstehungsvorgang der Ganglien glaube ich, daß dieser einer anderen Erklärung bedarf, als wie sie bisher gegeben worden ist. Wir werden darauf bei der Beurteilung der experimentellen Bildungen zurückkommen.

Als Beispiel führe ich ein Ganglion vom Fußrücken eines erwachsenen Mannes an.

Beobachtung 3. Der Bäckermeister S., 61 Jahre, bemerkte vor $1 \frac{1}{2}$ Jahren am äußeren Fußrücken eine kleine Anschwellung, in der er eine Krampfader vermutete. Die Anschwellung vergrößerte sich allmählich, besonders während der letzten Monate. Seit 3 Wochen vor der Aufnahme verspürte S. hier Schmerzen. Es handelt sich um eine cystische, traubenförmige Geschwulst des Fußrückens über dem proximalen Ende des Os metatarsale II.

Das Ganglion wird in Lokalanästhesie ausgeschält, es ist mehrkammerig und enthält eine schleimige, stark fadenziehende Flüssigkeit.

Das Ganglion ist im subcutanen Gewebe eingelagert, dessen Bindegewebe durch entzündliche Reize vermehrt ist. Die Wand der Hohlräume ist im.allgemeinen dünn, aber ungleich und besteht aus dichtem, fibrillärem. Bindegewebe, dessen. Fibrillen dick und plump aussehen. Blutgefäße finden sich in ihm nur sehr spärlich. In den Maschen des Bindegewebes fallen blaßgelb gefärbte, bröcklige Massen auf, in denen Bindegewebszellen liegen. Nach der Oberfläche zu wird diese Gelbfärbung ausgedehnter und intensiver, um schließlich die Rotfärbung des Bindegewebes vollständig zu verdrängen. In diesen Partien sieht man ausschließlich junge Bindegewebszellen. Gegen den Hohlraum wird die Wand, an einzelnen Stellen deutlicher als an anderen, von zur Oberfläche parallei gestellten Bindegewebszellen abgegrenzt. Sie liegen nicht überall dicht aneinander und sind länglich bis kubisch und intensiv färbbar.

Auf der Wand sind noch in der Organisation begriffene, fibrinähnliche, gelb gefärbte Massen vorhanden. Innerhalb der Wand erkennt man hier und dort in den Gewebsspalten noch schwach gelb gefärbte Reste des Niederschlages, zu denen die Bindegewebszellen in enge Be- 
ziehung getreten sind. Die Abgrenzung gegen die Höhle wird durch eine mehr oder weniger deutliche, einschichtige Lage schmaler Bindegewebszellen gebildet. Die Wand selbst besteht, wie bei den vorher beschriebenen Präparaten, aus dichtem, parallelstreifigem Bindegewebe mit plumpen, dicken Bindegewebsfibrillen. Die Analogie mit dem Hygrom ist weitgehend, nur sind die Proliferationserschènungen weniger intensiv. Der innere Abschluß der Wand geschieht hier wie dort durch Bindegewebszellen, die meistens flach, kettenförmig aneinandergereiht sind. Andere haben noch hohe, kubische Formen und nehmen die Hämatoxylinfärbung intensiver an. Der Inhalt ist dickflüssiger als der des Hygroms, eine chemische Untersuchung desselben wurde nicht vorgenommen. Das Ganglion ist umgeben von Fettgewebe, besondere Gefäßveränderungen habe ich in den untersuchten Schnitten nicht feststellen können, dagegen ist das bindegewebige Stratum des Fettgewebes durch chronisch-entzündliche Veränderungen vermehrt.

Ähnelt das Ganglion als irritative Bildung im Vorhandensein des Zellabschlusses und durch das Vorkommen der Niederschläge mehr dem Hygrom, so erinnert die folgende Beobachtung, ein subcutaner Iympherguß, wieder mehr an den Schleimbeutel.

Beobachtung $4^{1}$ ). Ein 33jähriger Herr erlitt durch Sturz vom Pferde am 29. VII. 1915 neben anderen Verletzungen einen „Bluterguß ${ }^{\circ 6}$ am rechten Oberschenkel. Im Juli 1916 wurde an derselben Stelle ein „Muskelbruch" fest. gestellt, der aber außer gelegentlichen. Schmerzempfindungen, die zentral vom "Muskelbruch" nach oben zogen, keine besonderen Störungen verursachte.

Der am 13. VI. 1917 erhobene Befund stellte eine gut faustgroße, weiche Geschwulst an der Hinterseite des rechten Oberschenkels dicht unterhalb des Trochanter maior fest; an ihrer vorderen und hinteren Zirkumferenz wird sie durch eine sichelförmige Narbe begrenzt. Kein Funktionsausfall des Beines, nur bei Bewegungen des rechten Beines Spannungsgefühl in demselben.

Operation am 15. VI. 1917. Nach Bildung eines großen Hautlappens kommt man auf einen über handtellergroßen Hohlraum. Dieser enthält nur Spuren einer Flüssigkeit, seine Wände spiegeln wie eine Gelenkkapsel. Die der Fascia lata anliegende Wand ist sehr gefäßreich und läßt sich wie eine Pseudomembran von ihrer Unterlage abziehen. Sie ist viel dünner als die Wand an der der Haut zugekehrten Seite. Die Wunde wird wieder dicht vernäht.

Der Erguß bildet sich aber immer wieder und entleert sich spontan bis zum 30. VI. dreimal aus einer Öffnung am unteren Wundwinkel.

Um die Höhle zur Verödung zu bringen, wird in einer zweiten Operation am 3. VII. der bräunlich-wässerige Erguß entfernt. Auf der Wand sitzen überall Blutgerinnsel ziemlich fest, sie lassen sich nicht vollkommen abschaben. Nach Excision einiger Stückchen der Wand zur mikroskopischen Untersuchung wird ein Drain eingelegt und die Haut bis auf die Drainöffnung vernäht. Entlassung am 14. VII. in Heilung. Die Sekretion war in den ersten Tagen p. op. reichlich, hat aber völlig aufgehört.

Härtung der Gewebsstücke in Formalin, Einbettung in Paraffin, Färbung nach v. Gieson.

1) Bereits verwertet in A. Bier, Beobachtungen über Regeneration usw., IV. Abhandlung unter M. 18. Dtsch. med. Wochenschr. 1917, Nr. 34. 
Die mikroskopische Untersuchung der Wand ergab: Das der Subcutis anliegende Bindegewebe ist dicht, parallel gestreift und fascienartig. Es geht allmählich in ein mäßig kernreiches Bindegewebe über, dessen fibrilläre Struktur nach der Oberfläche zu sehr undeutlich wird. Die Rotfärbung der Zwischensubstanz nimmt von außen nach innen langsam ab, bis daß sie streckenweise fleckig, wie ausgewaschen erscheint. Ein Zellsaum an der Oberfläche ist nicht vorhanden. Die Kerne sind in der Tiefe schlank und spindelförmig. Weiter oberflächlich sehen sie größtenteils bläschenförmig aus. Das Gewebe ist ohne besondere Begrenzung gegen die Höhle, vielfach lockert sich die Grundsubstanz oberflächlich auf und wird vollständig farblos. In solchen Partien sind die Bindegewebskerne gequollen, eckig und unregelmäßig gestaltet. Sie sind zum Teil kaum noch mit stärkster Vergrößerung zu sehen, da sie das Hämatoxylin nur ganz schwach angenommen haben. Das Bindegewebe der inneren Wand (auf der Fascie) ist derber und dichter. Im übrigen sind die Verhältnisse genau dieselben wie an der der Haut zugekehrten Seite.

Aus der Operationsgeschichte erfahren wir, daß ein nènnenswerter Erguß nicht vorhanden war, sondern daß die Wände des Spaltes dicht aneinander gelegen haber. Auch hier ist die Frage angebracht wie bei dem Schleimbeutel, warum die Wände nicht miteinander verkleben. Die mikroskopische Beschaffenheit der Innenfläche und ihr feuchter, schlüpfriger Zustand lassen uns die gleiche Antwort wie dort finden. Die Flüssigkeit erhält den Spalt. Denn es ist kein besonderer, einen natürlichen Abschluß besorgender Zellbelag nach Art eines Endothels vorhanden. Strecken weise ist die Grundsubstanz aufgefasert und farblos, die Zellkerne büßen ihre Tinktionsfähigkeit ein und werden gequollen, gelappt und eckig. Histologisch betrachtet kann von diesen Partien aus eine proliferierende, die auseinanderliegenden Wände verschmelzende Tätigkeit nicht mehr erwartet werden. So bleibt denn der Spalt erhalten.

Der nach der Verletzung aufgetretene Erguß war ein mit Blut untermischter Lympherguß (Décollement traumatique). Er liegt im subcutanen Gewebe, sein Inhalt koaguliert nicht, wie das auch Gussenbauer für die Lymphextravasate verlangt. Ebenso entspricht das Rezidivieren den von Gussenbauer geforderten Symptomen. Die Ursache seiner Entstehung besteht in einer tangential wirkenden Kraft, die eine Abscherung der Cutis von der Unterlage herbeiführte und dadurch eine Gewebszerreißung mit nachfolgendem Lympherguß bewirkte. Der Erguß mag im Anfang größer gewesen sein; mit der Zeit werden diese, wie uns die weiter unten beschriebenen Tierversuche zeigen werden, kleiner an Masse, bis schließlich nur noch ein Spalt übrigbleibt. Endlich kommt ein Gebilde zustande, welches mit dem Schleimbeutel eine weitgehende Ähnlichkeit aufweist, und damit ist die Berechtigung gegeben, auch diesen Lympherguß mit den oben genauer beschriebenen Spalten und Cysten zusammenzustellen.

Die angeführten vier Beobachtungen haben weitgehende Gemeinsamkeiten. Sie liegen alle im subcutanen Bindegewebe. Dasselbe ist 
bei den pathologischen Bildungen von allen Untersuchern als gewuchert und verdickt beschrieben worden. Der Kernreichtum ist in der Wand des Hygroms am größten, während der Lympherguß nur eine geringe Kernvermehrung aufweist. Aber auch der ,normale“ Schleimbeutel ist überwiegend von einer derb faserigen. Wand ausgekleidet, deren innerste Lagen sogar eine Quellung aufweisen mit Zellen, die an Knorpelzellen erinnern. Das Gewebe befindet sich histologisch ohne die Zeichen einer Reizeinwirkung, infolgedessen ist von einer Zellwucherung oder ähnlichen Erscheinungen einer chronischen Entzündung nichts, weder in der Wand noch in ihrer näheren Umgebung, zu sehen. Der Schleimbeutel gehört ja auch zu den physiologischen (normalen), erworbenen Bildungen.

Geht aber ein solcher ruhender Schleimbeutel durch irgend eine Einwirkung in den Reizzustand über, dann machen sich die Folgen, bestehend in Kernwucherung und vermehrter Flüssigkeitsansammlung, bemerkbar. Auch die weitere Umgebung wird in gleicher Weise entsprechend beeinflußt, und dadurch kommt bei den Hygromen auch die Bindegewebsvermehrung der anstoßenden Gewebe zustande, in deren weiterer Folge dann leicht durch die Art der Reizwirkung auch endarteriitische Vorgänge zutage treten können. Da Hygrom und Ganglion ohne Zweifel zusammengehören, so gilt für das Ganglion dasselbe wie für das Hygrom: es ist eine im Reizzustand befindliche Höhlenbildung. Das angeführte Beispiel Beobachtung 3 bietet Bilder, die sowohl an den Schleimbeutel als auch an das Hygrom erinnern. Dadurch findet die histologische Struktur der Wand eines Ganglions leicht seine Deutung. Die Zellvermehrung ist an der Oberfläche deutlich, und die Zellen stellen sich dort parallel zu ihr, eine Decklage bildend, die aus einer einfachen Reihe oder einer mehrzelligen Schicht bestehen kann. Diese Parallelstellung zur Oberfläche entspricht einer Gesetzmäßigkeit, die wir häufig zu beobachten Gelegenheit haben. Die Zellvermehrung macht sich am intensivsten an der Oberfläche der Wand bemerkbar, es entsteht dort ein Granulationsgewebe durch Organisation eines Niederschlages aus dem flüssigen Inhalt des Hohlraumes. Deshalb finden wir an den pathologischen Höhlenbildungen auch eine verdickte Wand aus derbem Bindegewebe, während diese Membran an den physiologischen Bildungen fehlen kann. Dieser Niederschlag, das faserstoffartige Exsudat (Virchow), ist die Folge des Reizzustandes, er entstammt der Gewebsflüssigkeit, die den Hohlraum anfüllt. Seine Organisation geht ungleichmäßig vor sich, weshalb in der Wand des Hygroms noch Reste in der Tiefe zu finden waren, während seine Anwesenheit in ansehnlicher Schicht beim Ganglion noch an der Oberfläche offenbar ist.

So erklären sich auch die Bilder, die mit zu der Annahme geführt haben, daß als erster Vorgang einer Spaltbildung eine Verflüssigung 
gewucherten Bindegewebes anzusehen sei. Diese Auffassung entspricht derjenigen, welche die meisten Untersucher pflegen. Lange mak leitet das Fibrinoid als Degenerationsprodukt des Bindegewebes von aufgelöstem Collagen her, das vorher im UUbermaß aufgetreten war. Die Bindegewebshyperplasie geht voran. Beim Ganglion spricht Ledderh o se von einer gallertartigen, kolloiden Degeneration, während Su mita Spaltbildungen allgemein aus hyperplastischem Bindegewebe durch primäre Nekrose und Verflüssigung der nekrotischen Massen mit nachfolgender Resorption entstehen läßt. Ricker unterstützt diese Ansicht. durch den Nachweis, da $B$ die Flüssigkeit durch Umwandlung der Bindegewebsfasern entsteht, nachdem vorher die Gefäße zugrunde gegangen' sind.

Payr konnte die primäre Schädigung und den Verschluß der Gefäße beim Ganglion nicht bestätigen. Die Gefäße werden vielmehr erst sekundär durch die chronisch traumatische Reizung endarteriitisch verändert, doch schreibt er von einem charakteristischen Einschmelzungsprozeß. Die Erweiterung physiologischer Lymphspalten durch Anhäufung des flüssigen Inhalts verbreitet dann die Einschmelzung in bis dahin noch unverändertes Gewebe. Das Ganglion ist eine Erweichungscyste.

Am weitesten entfernt sich Virchow von dem Standpunkt der primären Erweichung, indem er durch einen Akt der Atrophierung Lücken entstehen läßt, die zu selbständigen Kavitäten werden. Der Flüssigkeitserguß folgt dem Vorhandensein der Kavität. Die Wand wird. bei dauerhaftem Charakter der Bildung immer selbständiger.

So lassen sich zwei Ansichten mit fließenden Übergängen feststellen: einerseits primäre Degeneration und Verflüssigung des gewucherten Bindegewebes, wodurch ein mit flüssigem Inhalt gefüllter Raum entsteht, - andererseits primäre Hohlraumbildung durch einen Akt der Atrophierung mit anschließendem Flüssigkeitserguß. Durch die Beobachtung operativ entstandener Hohlräume und Spaltbildungen und durch erfolgreiche Versuche an Hunden hatten wir Gelegenheit, urs über die ersten Vorgänge ein Bild zu machen.

In einer Arbeit über die Regeneration der Fascie berichtete ich, daß nach Füllung von Defekten in subcutanem Gewebe mit physiologischer NaCl-Lösung regelmäßig Spaltbildungen eintraten. Die Füllung. von Defekten mit physiologischer NaCl-Lösung wurde von A. Bier auch zur Füllung von Defekten anderer Gewebe benutzt, und auch dabei war die Bildung von Höhlen und Spalten eine nicht seltene Beobachtung. Dies gab Veranlassung, die Bedingungen und den Vorgang ihres Entstehens genauer zu studieren.

Allen Spaltbildungen war zunächst der Sitz gemeinsam: das subcutane Bindegewebe war breit eröffnet, es war in großer Ausdehnung 
defekt, und dieser Defekt bildete einen großen Teil der Höhlenwandung. Der Inhalt bestand aus einer klaren, mehr oder weniger gelbbraun gefärbten Flüssigkeit, welche zum Teil deutlich nachweisbar Synovin enthielt und neben roten Blutkörperchen Lymphocyten, Körnchenkugeln und Leukocyten aufwies. Es handelte sich um Gewebsflüssigkeit, welche die eingefüllte $\mathrm{NaCl}-\mathrm{Lösung}$ ersetzt. Zeichen einer Gerinnung dieses. Inhaltes, solange er in der Höhle war, wurden nicht beobachtet, trotzdem die Farbe eine Beimischung von Blut zweifellos machte. Dies ent. spricht der Forderung Gussenbauers, daß der Inhalt von Lymphextravasaten trotz eines eventuellen Gehaltes an Blut nicht gerinnen darf. War nur ein Spalt vorhanden, so waren die Wände desselben feucht und sehr gleitfähig; das die Feuchtigkeit erhaltende Medium zog Fäden. Schließlich bildete bei allen eine grauweiße Membran die innere Auskleidung des Hohlraumes. Soweit besteht makroskopisch nach allen Richtungen eine weitgehende Übereinstimmung zwischen den durch NaCl-Füllung verursachten Höhlen- und Spaltbildungen unter sich, wie auch zwischen diesen einerseits und dem beschriebenen Schleimbeutel, Ganglion, Hygrom und Lympherguß andererseits.

Für die histologische Untersuchung benutzten wir Präparate von Hunden. Die Operation gestaltete sich so, daß von einem Längsschnitte am Rücken unter der Cutis das subcutane Gewebe in großer Ausdehnung entfernt wurde, so daß zwischen Cutis und Muskulatur alles Gewebe entfernt war. Schien nun die Höhle nicht groß genug, so daß sie möglicherweise nicht erhalten bleiben würde, so schnitten wir aus der Muskulatur noch ein in der Fläche entsprechendes, in der Tiefe weit. in die Muskelmasse hineinreichendes Stück heraus. Die Blutung wurde durch Unterbindung und Tamponade gut gestillt, und dann die Höhle mit physiologischer NaCl-Lösung reichlich gefülit, so daß nach der genauen Hautnaht eine schwappende, subcutane Flüssigkeitsansammlung bestand. Die gewünschte Höhlenbildung tritt so mit Sicherheit $\left.\operatorname{ein}^{1}\right)$. Die Präparate entnahmen wir am 10., 15. und 19. Tage, sie wurden in Formalin oder Alkohol gehärtet, in Paraffin eingebettet und nach v. Gieson gefärbt. Zum Nachweis des Fibrins wandten. wir die Weigertsche Fibrinfärbung an.

Beobachtung 5. Operation am 14. V., Präparat entnommen am 25. V. 1918. Es besteht eine große subcutane Flüssigkeitsansammlung an der Operationsstelle. Nach Eröffnung der Höhle entleert sich eine große Menge blutig-seröser Flüssigkeit, die im Reagensglase nach längerem Stehen gelatinös wird und leicht. Fäden zieht. Die Wandung der Höhle ist spiegelnd, glatt, von grauweißer Farbe.

1) Später hatte ich bei einem Hunde Gelegenheit nachzuweisen, daß der Erguß in einer so entstandenen Höhlenbilding nach vollständiger Entleerung durch Punktion mit einer großen schwappenden Flüssigkeitsansammlung rezidiviert. In diesem Rezidiverguß war reichlich Synovin chemisch nachweisbar (Geheimrat Salkows ki). 
Die chemische Untersuchung der Flüssigkeit auf Synovin ließ sein Vorhandensein nicht ausschließen (Geheimrat Salkows ki).

Mikroskopischer Befund (Abb. 1): Am äußeren Rande des Präparates, der Höhle abgekehrt, liegt ein schmaler Streifen quergestreifter Muskulatur und darüber ein fascienartiges Bindegewebe. Von hier ausgehend ist junges Granulationsgewebe dabei, einen gelb gefärbten Niederschlag zu organisieren, nicht gleichmäßig, sondern es werden von bereits organisierten Partien gelbe Streifen und Inseln eingeschlossen, in denen einige eingewanderte Leukocyten und Lymphzellen zu sehen sind. Durch die Rotfärbung der bindegewebigen Elemente sind die älteren Teile des Granulationsgewebes in der Tiefe deutlich von den jüngeren und jüngsten an der Oberfläche unterschieden. Im Granulationsgewebe finden sich die bekannten Zellformen, unter denen dje polynucleären Leukocyten zurücktreten. Der Niederschlag ist fädig, wabenartig mit Lücken durchsetzt und enthält stellenweise polynucleäre Leukocyten, aber keine roten Blutkörperchen. Die von Granulationsgewebe eingeschlossenen Reste sind hyalin gequollen, man vermißt die feine, fädige Struktur des frei an der Oberfläche liegenden Niederschlages. Die Oberfläche ist ungleich begrenzt. Während hier eine dichtere Lage großer Fibroblasten den Abschluß besorgt, fehlt an anderen Stellen jegliche. Andeutung einer Begrenzung. Das junge Granulationsgewebe geht unter deutlicher Auflockerung in den flüssigen Inhalt über. Dabei finden sich hier und dort ebenfalls noch oberflächliche Niederschlagsreste. An wieder anderen Partien liegt auf dem Gewebe eine dicke Schicht des mattgelb gefärbten Ausscheidungsproduktes.

Beobachtung 6. Operation am 12. VI., Präparat entnommen am 27. VI. 1918. Es besteht eine große subcutane Höhle, deren Wände von einer graugelben, sehr weichen Masse belegt sind. Sie enthält eine leicht rötlich gefärbte, wässerige Flüssigkeit, welche nach längerem Stehen im Reagensglase gallertartig gerinnt.

Mikroskopischer Befund (Abb. 2): Die Innenwand, welche im subcutanen Gewebe liegt, ist sehr viel zellreicher als die der Beobachtung 5. Die Grundsubstanz färbt sich schwach rot. Die Bindegewebsfaserbildung ist in der Tiefe deutlich und nimmt nach der Oberfläche zu ganz allmählich ab. Überreste des gelben Niederschlages, welcher in erheblicher Menge in der Höhle noch zu sehen ist, finden sich noch als gelb gefärbte Bröckel ziemlich weit von der Oberfläche im Gewebe. Eine besondere Neigung polynucleärer Leukocyten zu diesen Bröckeln ist nicht festzustellen, trotzdem sich diese in reichlicher Menge im Gewebe vorfinden. An der Oberfläche treten hier und dort größere Massen von Niederschlägen auf; Bindegewebszellen, Leukocyten dringen in sie ein, um sie zu organisieren. Die Grenze des Hohlraumes wird durch eine mehrfache Lage großer, blasiger, junger Bindegewebszellen mit langen Ausläufern gebildet, zwischen denen eine reichliche Zahl polynucleärer Leukocyten vorgefunden wird. Junge Blutgefläße treten hier bis dicht an die Oberfläche heran. Die in der Wand eingeschlossenen gelben Niederschläge geben offenbar in voller Ausdehnung die Fibrinreaktion. Es muß erwäbnt werden, daß die Entwicklung der Innenwand nicht überall gleichmäßig ist. Vielmehr finden sich auch hier noch Ü̉bergangsbilder von der beginnenden Organisation des Niederschlages bis zu dem beschriebenen Entwicklungsstadium der Höhlenauskleidung.

Beobachtung 7. Operation am 24. VI., Präparat entnommen am 13. VII. 1918. Von außen ist eine Flüssigkeitsansammlung nicht mehr zu erkennen, auch beim Betasten fühlt man an keiner Stelle Fluktuation. Nach Spaltung der Haut findet sich im subcutanen Gewebe ein Spaltraum, dessen Wände grauweiß, spiegelnd, glatt und feucht-glänzend sind. Eine Flüssigkeit in meßbarer Menge ist nicht vorhanden. Die auskleidende Membran läßt sich als feine Haut von der Unterlage unter Substanzverlust des umgebenden Gewebes abziehen. Die Ober- 
fläche der Wandung ist nicht gleichmäßig, sondern es bestehen Vorsprïnge und wulstförmige Vorbucklungen.

Mikroskopischer Befund (Abb. 3): Auf dem subcutanen Fettgewebe ist nach dem Spaltraum zu ein zartes, lockeres, maschiges Bindegewebe entstanden, dessen Kerne noch mehr oder weniger bläschenförmig sind. Der Zellgehalt ist groß. Nach der Oberfläche zu nimmt das.Gewebe wieder einen dichteren Charakter an und ist wieder stärker rot gefärbt. Der Zellreichtum ist hier im wesentlichen noch der gleiche wie in dem lockeren Gewebe. Während an einem Teil der Wand die Rotfärbung bis dicht an die Oberfläche dieselbe bleibt, um dann wieder um ein geringes blasser zu werden, finden wir an anderen Stellen, daß das lockere Gewebe bis dicht unter die Oberfläche vordringt und nur von einer schmalen, nur wenig festeren Gewebsschicht mit blaßroter Färbung begrenzt wird. Die Bindegewebsfibrillen sind überall deutlich ausgeprägt. Die Oberfläche selbst wird durch eine ein- oder mehrschichtige Lage großer, vollsaftiger Zellen gebildet, welche die Färbung mit Eisenhämatoxylin im Kern und Protoplasma intensiv annehmen. Sie sind meistens spindelförmig, mit lang ausgezogenen Enden und entstammen den Fibroblasten. Auf dieser Zellschicht liegt noch deutlich ein feines Häutchen gelbbrauner Masse. Bei starker Vergrößerung erkennt man fast überall dicht unter der Oberfläche fein gelb gefärbte Streifen als Reste des Niederschlages. In der neugebildeten Wand sind Blutgefäße im allgemeinen nur spärlich.

Aus den mikroskopischen Bildern haben wir als Entwicklungsgang zu entnehmen, daß die künstlich geschaffene Höhle mit einer so wenig wie möglich differenten Flüssigkeit angefüllt ist. Diese Höhle liegt zum größten Teil im subcutanen Gewebe, dessen Lymphgefäßsystem und Spalten in großer Ausdehnung geöffnet worden sind. Da die Blutung fast vollständig gestillt war, so weit man technisch dazu in der Lage ist, so kann die nachträglich noch aussickernde Menge Blutes nur gering sein. Die physiologische $\mathrm{NaCl}-\mathrm{Lösung}$ wird nach unseren Untersuchungen durch eine Gewebsflüssigkeit ersetzt, in der beim Menschen mehrfach Synovin festgestellt wurde, beim Hunde das Vorhandensein desselben nicht mit Sicherheit auszuschließen war. Die Flüssigkeit verhält sich nach der Forderung Gussen bauers wie ein Lymphextravasat: sie gerinnt nicht im Körper, trotz Beimischung von Blut. Aus der Gewebsflüssigkeit wird eine festere Substanz abgeschieden, die sich wie Fibrin verhält und welche sicherlich zum guten Teil aus Fibrin besteht, da in ihr die Fibrinreaktion in ausgedehntem Maße auftritt. Der Niederschlag wird nun durch das bekannte Granulationsgewebe organisiert, doch nicht gleichmäßig und vollständig, sondern es bleiben Streifen und Inseln von ihm im Granulationsgewebe zurück, welche aufquellen und sich mit Pikrinsäure leuchtend gelb färben. Diese werden nach und nach immer mehr resorbiert und organisiert, bis schließlich nur noch feine Fäden mit starken Systemen in der fertigen Wand des Spaltraumes erkennbar sind. Ihnen liegen vielfach Zellen an, die manchmal zum Teil in dem gelben Niederschlagsreste, zum andern Teil in der bindegewebigen Masse liegen, ohne daß man nach der Entstehungsgeschichte und ihrem Aussehen annehmen darf, daß diese Zellen in Degeneration begriffen sind. 
Schon früh wandern Fibroblasten bis an die Oberfläche des Hohlraumes. Die Organisation des Niederschlages hat noch kaum nennenswert Platz gegriffen, und schon sehen wir eine geordnete Reihe dunkler gefärbter, gequollener Fibroblasten den Abschluß des festen Maschenwerkes gegen die Flüssigkeit besorgen. Allmählich wird diese Reihe deckender Zellen dichter, die Zellen vollsaftiger, größer und zahlreicher, so daß eine mehrschichtige Lage solcher deckender Zellen entsteht. Schließlich sehen wir auf dieser Zellage einen Saum gelben Niederschlages, der offenbar von neuem aus der Flüssigkeit abgesetzt wurde, oder aber aus der die Wände benetzenden Flüssigkeit besteht, welche bei der Fixierung geronnen, die aber intra vitam flüssig ist.

Das. Granulationsgewebe trägt zunächst keinerlei besondere Merkmale. Auffällig ist nur gegen Ende der Beobachtung - 19 Tage -, daß die Innenschicht der Wand kaum Gefäße enthält. Dies entspricht sowohl unseren mehrfachen Beobachtungen an älteren Spalt- und Hohlräumen, als auch der Angabe Payrs, daß die Innenschicht arm an Capillaren ist.

So sind die in der Wand von Hohl- und Spalträumen auftretenden gelben Massen, Streifen und Inseln, nicht die Produkte von degenerierenden, in Verflüssigung befindlichen, gequollenen Zellen, sondern es sind dies die Reste des aus der Gewebsflüssigkeit stammenden Niederschlages, den wir in dem 10 Tage alten Präparat noch unzweideutig in großer Menge festgestellt haben.

Für die weitere Entwicklung stehen uns ein 7 und 8 Wochen alter Spaltraum beim Menschen zur Verfügung.

Beobachtung $8^{1}$ ). Patientin 35 Jahre alt. Weichteilsarkom an der Außenseite des rechten Oberarmes. Nachdem der Tumor im Gesunden entfernt war, zeigte sich bald ein lokales Rezidiv. Deshalb erneute Operation. Lappenschnitt lateral von der Geschwulst. Der Lappen wird zurückpräpariert. Aus der Oberarmmuskulatur wird das Rezidiv so herausgeschnitten, daß der periostlose Oberarmknochen den Grund der großen Höhle bildet, an den Seiten die Muskulatur und nach außen das Unterhantzellgewebe breit freiliegen. Die Höhle wird mit physiologischer NaCl-Lösung angefüllt und gut vernäht.

Nach 14 Tagen tropft aus Fadenöffnungen etwas stark fadenziehende, bräunlich-seröse Flüssigkeit ab. Am unteren Ende der Narbe ist Fluktuation deutlich fühlbar.

7 Wochen nach der Rezidivoperation muß erneut eingegangen werden ${ }^{2}$ ). Die ganze Gegend unter dem Hautlappen ist ziemlich tief eingesunken. Die alte Hautnarbe wird wieder gespalten, und unter dem Lappen findet sich ein wohlausgeprägtes Unterhautzellgewebe. Dicht unter $\mathrm{ihm}$ liegt eine etwa $5 \mathrm{~cm}$ lange, flache Höhle, deren innere Fläche mit einer geringen Menge stark schlüpfriger, fadenziehender Flüssigkeit benetzt ist. Frei in der Höhle liegt ein etwa $2 \mathrm{~cm}$ langer, gut stricknadeldicker Körper, von grauer Farbe und weicher Beschaffenheit.

1) Bereits verwertet in A. Bier, Beobachtungen über Regeneration usw., 18. Abhandlung. Dtsch. med. Wochenschr. 1918. Unter M. 38.

2) Die Höhlenbildung rezidivierte nach dieser Operation. 
Die Höhlenwandung wird entfernt. Teile derselben werden in Formalin und Alkohol, der freie Körper nur in Alkohol fixiert.

Mikroskopischer Befund: Die Wand besteht aus Bindegewebe, welches in der Tiefe leuchtend rot, nach der Oberfläche zu allmählich blasser werdend, in der obersten Schicht blaßrosa gefärbt ist. In der Tiefe ist das Gewebe sehr gefäßreich und von deutlich fibrillärer Struktur. Die einzelnen Bindegewebsfasern stehen im wesentlichen der Oberfläche parallel. Entsprechend der Rotfärbung ist die Fibrillenbildung in der Tiefe ausgesprochen, in den obersten Schichten dagegen ganz undeutlich. Die in der Tiefe mehr spindelförmigen, schmalen Bindegewebszellen werden nach der Oberfläche zu groß und bläschenförmig. Zwischen diesen Fibroblasten liegen hauptsächlich kleine, rundkernige Lymphzellen, besonders an den GefäBen. An der Oberfläche, welche ohne bestimmte Grenze oder deckende Zellschicht in unregelmäßiger Linie verläuft, finden sich die Zellen etwas zahlreicher und dichter gelagert. An vielen Stellen dieser obersten Schicht sieht man zwischen den Zellen gelb bis gelbbraun gefärbte, bröcklige, hyaline Massen, von größeren Klumpen bis zu kleinen Streifen. In ihnen finden sich neben den schon erwähnten Zellelementen auch vereinżelte, polynucleäre Leukocyten eingelagert. An einer Stelle der Wand ragt ein zottenförmiges Gebilde in das Lumen hinein, welches aus ebensolchen gelben hyalinen Massen besteht und der Oberfläche mit breiter Basis aufsitzt. Es ist durchsetzt mit Spalten und Hohlräumen. Von der Basis aus dringen Zellen zur Organisation in die Zotte ein und Iösen die hyaline Masse büschelförmig auf. Das Gebilde ist durchsetzt mit kleinen, rundkernigen Lymphzellen. Bei der Fibrinfärbung nach Weigert sind in der Wand, entsprechend dem Befunde an den v. Gieson-Präparaten, fädige Fibrinmassen in geringer Menge nachzuweisen, wobei zu bemerken ist, daß die Wand des in Alkohol fixierten Präparates in ihrer Entwicklung noch wesentlich hinter der des ersteren zurück ist. - Der freie Körper besteht im wesentlichen aus gelb gefärbter, fädiger bis hyaliner Masse. Inmitten derselben treten kernlose, blaßrosa gefärbte Bindegewebsinseln auf, in welchen die fibrilläre Struktur noch zu erkennen ist. Über das ganze Präparat sind zahllose Leukocyten und große Lymphzellen mit blasigem Kern und einer Membran (Körnchenkugeln) verstreut. Fibrin findet sich an den Rändern in zierlichen Fäden bis zu plumpen Massen, während im Innern nur an einzelnen Stellen noch eine schwächere Fibrinreaktion an gequollenen Fäden auftritt.

Beobachtung 8. H. $\left.{ }^{1}\right) 34$ Jahr. Sarkom im muscul. vastus lateralis. Exstirpation des Tumors, indem der Muskelbauch in voller Stärke reseziert wird. Die Höhle wird in der Tiefe rom Zwischenmuskelgewebe, oben und unten von den Muskelstümpfen und außen vom Unterhautzellgewebe begrenzt, welches in großer Ausdehnung freiliegt. Zur Füllung der Höhle werden $150 \mathrm{ccm}$ physiologischer NaCl-Lösung gebraucht.

Nach 10 Tagen ergibt eine Probepunktion des fluktuierenden Tumors blutigseröse Flüssigkeit, die rote Blutkörperchen und Leukocyten in vermehrter Zahl enthält.

4 Wochen p. op. noch deutlich Fluktuation.

8 Wochen p. op. erneute Operation wegen Rezidivverdachtes. Von einer Lücke ist nichts zu fühlen, auch keine Fluktuation. Dicht unter der Fascie findet sich eine 6,2 cm lange Höhle mit einem knappen EBlöffel voll seröser Flüssigkeit. In ihr liegt frei ein bohnengroßes, nierenförmiges Körperchen, dessen Durchschnitt braunrot ist. Es ist mit einer grauweißen Membran überzogen. Die Höhle ist mit einer glatten Haut ausgekleidet. Stücke der Wand wie auch je eine Hälfte des freien Körperchens werden in Formalin und Alkohol gehärtet.

1) Bereits verwertet in A. Bier, Beobachtungen über Regeneration usw., 18. Abhandlung. Dtsch. med. Wochenschr. 1918 unter M. 33. 
Mikroskopischer Befund: Stück der Wand der Muskelseite.

Die Wand, welche der muskulatur direkt aufliegt, besteht in der Tiefe aus einem derben Bindegewebe, welches sehr rasch locker wird, zahlreiche Gefäße enthält und in der Tiefe eine zierliche, parallele Faserung aufweist. Seine Rotfärbung wird nach der Oberfläche zu immer blasser, bis schließlich die Zwischensubstanz nur noch einen rosa Hauch hat und von einer Ausbildung von Bindegewebsfasern wie in der Tiefe nichts mehr erkennen läßt. Das Zwischen: gewebe ist dicht unter der Oberfläche homogen und birgt neben runden Zellen wie im Granulationsgewebe eine große Zahl junger Bindegewebszellen von schlanker, spindliger Form mit bläschenförmigem Kern. Die jungen Gefäße halten sich in mehr oder weniger weitem Abstande von der Innenfläche. In der innersten Zone sieht man deutlich gelbe, kleinste Fleckchen und Fäden, welche nach dem Hohl. raum zu an Masse schnell zunehmen, so daß die Oberfläche schließlich von einem dichten Maschenwerk homogener, gelber Fäden gebildet wird, in welchem sich zahlreiche, junge Fibroblasten und Lymphocyten befinden. Die gelben Fäden in der Tiefe sind Reste des Niederschlages. Es sind nirgends Übergangsbilder einer Umwandlung von Bindegewebszellen zu solchen gelben Fäden vorhanden, sie liegen zum großen Teil, besonders weiter im Inneren der Wand, ohne jeden Zusammenhang mit Zellen im Zwischengewebe, An anderen Partien der Wand bietet die innere Zone das Bild eines organisierenden jungen Bindegewebes. Hier reichen die jungen Capillaren bis dicht an die Oberfläche heran. Die Oberfläche ist an diesen Partien schärfer begrenzt als an den erstbeschriebenen (älteren). Durch Fibrinfärbung läßt sich nachweisen, daß, wie die gelb gefärbten, feinen Fädchen, in der Tiefe ebensolche blau gefärbte Massen im Gewebe liegen, wenn auch an der Oberfläche die Fibrinreaktion viel weniger umfangreich auftritt als die Gelbfärbung in den v. Gieson-Präparaten.

Nierenförmiges Körperchen:

Es besteht im Inneren im wesentlichen aus zusammengebackenen, ausgelaugten, roten Blutkörperchen mit zahlreichen, sehr blassen, großen Lymphzellen (Körnchenkugeln). Um diese Masse herum, im allgemeinen ziemlich scharf von ihr getrennt, liegt eine bindegewebige Membran von wechselnder Stärke mit zahlreichen Fibroblasten und spärlichen Lymphocyten. Seine Oberfläche ist stellenweise nach außen scharf begrenzt, an anderen Stellen wieder unscharf, höckrig. Die Zellen sind an der Oberfläche gequollen, bläschenförmig und unförmig. In die Wand eingeschlossen findet sich reichliches Blutpigment, eine Fibrinreaktion ist in den untersuchten Schnitten nicht aufgetreten. Mitten in der gelben Masse sind alte Bindegewebsreste an der fibrillären Struktur und der blassen Rotfärbung zu erkennen. Sie enthalten keine Bindegewebskerne mehr. An einzelnen Punkten kann man verfolgen, wie von der Membran eine Organisation der gelben Masse ausgeht. Junge Fibroblasten dringen gegen das Innere vor, die Zwischensubstanz wird homogener und fädiger, sie wird blaß und farblos,

Beide Präparate sind in ihrem Aufbau auch jetzt noch nicht ganz fertig. Neben älteren Partien, wo die Bindegewebszellen schon mehr den Charakter der Spindelzellen, ihrer definitiven Form, angenommen haben, treffen wir auf solche, welche noch die Merkmale des jüngeren Granulationsgewebes tragen. Es scheinen immer wieder Lagen von Niederschlägen aufgeschichtet zu sein, die wieder organisiert werden, bis schließlich der Hohlraum zu einem feinen Spalt wird, dessen Wände nur noch feucht sind. 
Ein Zellsaum, wie bei den.Versuchspräparaten (Beobachtung 5 und 7 ) oder bei dem Hygrom (Beobachtung 2) und Ganglion (Beobachtung 3), ist nicht vorhanden. Das Gewebe der Innenwand macht auch kaum den Eindruck, als ob ein stärkerer Reiz vorgewaltet hätte. Die Gewebe nähern sich dem Typus des beschriebenen Schleimbeutels (Beobachtung 1), der ja auch von einem reizlosen Gewebe umkleidet ist. Die beiden Beobachtungen 8 und 9 stehen histologisch zwischen dem Schleimbeutel und dem Hygrom. Klinisch ist ihre nahe Verwandtschaft mit einem Lympherguß noch dadurch erwiesen, daß beide Spaltbildungen nach der Exstirpation rezidivierten.

Wenn, wie in den Beobachtungen 8 und 9, die Defekte zum großen Teil auch in der Muskulatur gelegen haben, so war doch bei der Herstellung der Höhlen das lymphgefäßführende Bindegewebe weit eröffnet und freigelegt. Es waren, wie Wolter es für die Entstehung von Lymphorrhagien angibt, massenhaft kleine und kleinste Lymphgefäße eröffnet. Die Gewebsflüssigkeit ergießt sich in die Höhle, ersetzt die physiologische NaCl-Lösung und bleibt in dem HohIraum flüssig. Der Erguß ist die Folge der Gewebstrennung. Damit stellen wir uns in Gegensatz zu den in der Literatur festgelegten Ansichten. Sind die morphologischen Beobachtungen der Autoren auch hier wieder zu bestätigen, so hat man bei ihrer Deutung allgemein als ersten Vorgang eine Verflüssigung des Bindegewebes angenommen. Schuchhardt glaubte den Nachweis zu führen, daß Hygrome durch eine eigentümliche Degeneration der Bindegewebszellen zustande kommen, ohne daß sie an das Vorhandensein von Schleimbeuteln gebunden sind. Er fand in der Wand jene auch von uns aufgefundenen gelben Massen, in denen weiter nach der freien Höhle zu Fibrinfäden auftreten, und welche Schuchhardt als gequollene Bindegewebsfasern auffaßt. An die äußere Schicht der Sackwand des Hygroms, in der Bündel von Spindelzellen liegen, schließt sich eine Zone, in der die Spindelzellen anschwellen und, nach der Abbildung Sohuchhardts ${ }^{1}$ ), Form und Aussehen von Fibroblasten annehmen. Ja, Schuchhardt gibt in dieser Zone das besonders reichliche Vorhandensein von Mitosen an. Wenn nun diese Zellen einem Quellungs- und Degenerationsprozeß verfallen sein sollten, dann müßte man doch das Vorkommen von zerfallenden oder degenerierenden Kernen erwarten. Aber Schuchhardt hebt besonders hervor, daß die Kerne in den gequollenen Massen noch zunächst wohlerhalten und gut färbbar sind. Später sollen dann die Kerne völlig verschwinden, obwohl Schuchhardt Ưbergänge dafür nicht angibt: Die degenerierenden Zellen werden nur immer voluminöser, es scheiden sich in ihnen Fibrinfäden ab, und schlieBlich wird die gequollene homogene Masse verflüssigt. Das ist dann der Inhalt des Hygroms.

1) Siehe Virchows Archiv, 121, Tafel III, Abb. 3. 
Es ist unzweifelhaft, daß die gelben „den hyalinen Zylindern der Niere vergleichbaren" Massen nichts anderes sind, als Niederschläge aus dem flüssigen Hygrominhalt, in welche die Fibroblasten einwandern, um sie zu organisieren. Das beweisen die Bilder aus unseren Tierversuchen. Das Vorkommen von Fibrin zwischen und in diesen Niederschlägen, welches nach innen zu an Masse zunimmt, beweist weiter nichts, als daß auf die vorhandene, entzündliche Reizwirkung ein vermehrter Erguß auftritt, aus dem dann auf der Wand ein Niederschlag abgesetzt wird, welcher Fibrin enthält, vergleichbar der diphtherischen Membran. Dieser Niederschlag wird in unregelmäßiger Weise organisiert, so daß zwischen den proliferierenden Zellmassen Inseln und Streifen homogener Reste liegenbleiben, in denen das Fibrin schon so weit verändert ist, daß es keine Färbungsreaktion mehr gibt, und in welche nur ver- einzelte Fibroblasten eingedrungen sind. Diese Erklärung erscheint mir ungezwungener, einfacher und aus den angeführten Angaben Schuchhardts auch leichter verständlich.

Ricker verneint, wie Schuchhard t, den Zusammenhang zwischen Schleimbeutel und Hygrom und meint, daß beide nur gewisse Lieblingsstellen gemein haben. Er führt im Verein mit den verschiedensten pathologischen Bildungen den Nachweis, daß die gelben Massen in der Wand von Hygromen verflüssigtes Bindegewebe seien. UUber die Einheitlichkeit des Vorganges an allen den dort angeführten Objekten soll hier nicht geurteilt werden. Für die Hygrome und Ganglien aber glaube ich, aus den Versuchen und den operativ herbeigeführten Spaltbildungen an Menschen, deren Entwicklung wir klar vor Augen haben, den Beweis zu erbringen, daß es sich nicht um eine Degeneration des Bindegewebes, sondern um einen in langsamer Organisation befindlichen Niederschlag aus dem flüssigen Inhalt handelt. Der Utbergang gelber und roter Faserteile erklärt sich'aus dem Organisationsvorgang, bei dem in der zu organisierenden Substanz von den Fibroblasten collagenes Bindegewebe in der den Mutterboden darstellenden, gelb gefärbten Substanz gebildet wird. Die gelben Flächen entstehen demnach nicht durch Zusammenfließen feiner, gelber Fäden, sondern das eindringende Bindegewebe löst die gelbe Fläche beim Vordringen in Fäden auf. Wir erkennen ja aus den Tierversuchen, die uns die ersten Stadien mit vollster Deutlichkeit zeigen, daß der Niederschlag, die gelbe Masse, zuerst da ist, bevor überhaupt von Bindegewebe die Rede sein kann. Die Organisation geht nur langsam und unregelmäßig vor sich, vielleicht weil stärkere Reize fehlen. Dafür spricht das Fehlen jeglicher zelliger Infiltration. Es müßte eigentlich wundernehmen, daB ein so destruierender Prozeß, in dessen Umgebung die Gefäßversorgung anfänglich noch so gut ist, ohne zellige Infiltration vor sich gehen sollte.

Die bei den Hygromen beschriebene Vorwölbung und der dort eben- 
falls beobachtete, frei durch das Lumen ziehende Gewebsbalken sind, wie aus dem Granulationsgewebe erkenntlich, nicht durch konzentrische Verflüssigung der Wand im Stadium der Querschnittsverminderung, sondern sie werden durch Auflagerung und Organisation stärker. Solche Auflagerungen können ebenfalls zottenförmig in das Lumen hineinragen wie das Präparat der Beobachtung 8 beweist. Vorsprünge und Balken finden sich schließlich auch im 3. Tierversuch (Beobachtung 7), bei dem die Oberfläche des Spaltraumes schöne, große Zotten aufweist.

Noch besser beleuchten diesen Vorgang die in den Beobachtungen 8 und 9 gefundenen freien Körper. In der Mitte beider, gleichsam als Krystallisationspunkt, konnten wir abgestorbene Bindegewebsmassen feststellen, um die die gelbe Mașse niedergeschlagen war. In dem jüngeren Präparate, Beobachtung 8, treffen wir nur Lymphzellen und Leukocyten, Zellen, die gelegentlich auch in der freien Flïssigkeit angetroffen werden. Außen um den älteren, größeren Körper, Beobachtung 9, haben wir eine Membran aus jungem Bindegewebe gefunden, bei dem das jüngere Gewebe an der Innenseite der Membran liegt. Wenn der Einschmelzungsprozeß an der Oberfläche vollendet wird, so müßte das gelb gefärbte Einschmelzungsprodukt nicht innen, sondern außen liegen. Es ist aber gerade umgekehrt. Die Rickersche Beweisführung trifft nicht zu, sondern bei den Hygromen aus Ganglien ebenso wie bei den anderen, hier angeführten Bildungen halte ich den Vorgang in gerade umgekehrtem Sinne für erwiesen, alst wie ihn Ricker annimmt.

Payr erklärt an der Hand histologisch genau beschriebener Präparate karpaler Ganglien, wie die Entartung des Bindegewebes in der Wand vor sich gehen soll. In der Abbildung des Falles $9^{1}$ ), welchen $\mathrm{Pa} \mathrm{yr}$ zu den schönsten und lehrreichsten seiner Sammlung zählt, stellt er ein Stück der Wand dar, welches ich auf Grund meiner experimentellen Erfahrungen und der an den Präparaten gesehenen Bilder anders beurteilen möchte als er. Auf der Innenfläche liegt ein Saum eines Niederschlages mit großen, intensiv gefärbten Fibroblasten, welcher ohne Be* grenzung in den flüssigen Inhalt übergeht, dann folgt eine breitere Lage jungen Bindegewebes mit einer im wesentlichen homogenen Grundsubstanz und einer Andeutung fibrillärer Struktur. Weiter nach außen schließt sich eine dritte Schicht an, in der noch Niederschlagsreste vorhanden sind, welche organisiert werden. Soweit die morphologische Beschreibung in Frage kommt, glaube ich, aus dem Bilde und der Erklärung Payrs nichts zu finden, was meiner Deutung im Wege stände. Der Niederschlag wird tatsächlich ungleich organisiert, wie das bei verschiedenen Gelegenheiten bereits vermerkt ist. Es können also sehr gut in der Tiefe noch in der Färbung veränderte Massen vorhanden sein, wenn darüber bereits junges Bindegewebe gebildet ist. Auch Payr

1) Siehe Dtsch. Zeitschr. f. Chir. 49, Tafel III/IV, Abb. 6.

Virehows Archiv. Bd. 228. 
beschreibt die in der Tiefe der Wand vorhandenen, körnigen Massen als schwächer blau gefärbt. Sie sind ja auch der Resorption verfallen. Bei der v. Gieson-Färbung verhält sich der hyalin gewordene Niederschlag, wie auch das Fibrin, anders als der frische, er wird leuchtender gelb, dann braungelb, um schließlich bei zunehmender Resorption die Färbung wieder ganz zu verlieren. Über die großen, homogen gewordenen, riesigen Zellen verweise ich auf meine Schuchhardt gegenüber gemachten Ausführungen. Die an der Oberfläche, in Quellang und Auflösung befindlichen Elemente sind der Wirkung des Inhaltes verfallen. In den Bemerkungen über die Schleimbeutel (Beobachtung 1) und den Lympherguß (Beobachtung 4) habe ich zu diesem Vorgang Stellung genommen. Auch Payr sagt in den Ausführungen zu Fall 13, daß der Einschmelzungsprozeß nicht nur Folge der Veränderungen im Gewebe der Ganglienwand ist, sondern auch möglicherweise vom Inhalt aus derartigen Veränderungen an einzelnen Stellen der Wand hervorgerufen oder begünstigt werden können. Es ist zuzugeben, daß die Beurteilung durch die experimentellen Beobachtungen wesentlich erleichtert wird. Die Versuche führen uns aber zwingend zu der entgegengesetzten Auffassung, als wie sie bisher gegolten hat.

Die Entstehung der Gelenke ist dasVergleichsobjekt für die Entstehung der in Frage stehenden, erworbenen Spaltbildungen gewesen. Wir meinen mit Unrecht. Ich glaube nicht, daß man den embryonalen Entstehungsmodus auf die erworbenen, zum großen Teil noch dazu pathologischen Bildungen anwenden darf. Lehnt man doch für die Wundheilung und die Regeneration den Vergleich mit den embryonalen Vorgängen mit Recht ab.

Allen Spaltbildungen, den erworbenen (Schleimbeutel, Hygrom, Ganglion, Lymphorrhagie) wie den experimentellen (Hundeversuch, Beobachtung 8 und 9) ist die breite Eröffnung des lymphgefäßführenden Gewebes, im wesentlichen des subcutanen Bindegewebes, gemeinsam. Dieser Sitz, der auch in der Literatur gebührend beachtet worden ist, hat zu der vorübergehenden Annahme geführt, daß das Fettgewebe einen wesentlichen Anteil an der Bildung der Ganglien haben müßte. Daher finden auch bei allen Gelegenheiten, wo das Gewebe in seinen Zusammenhängen Zerreißungen oder Dehnungen erfährt, Ergüsse von Gewebsflüssigkeit eine einfache Erklärung. Wenn daher Sumita schreibt, daß Pressung, Zerrung und Utberdehnung oder Blutansammlung in einer vorhandenen Gewebsspalte Momente für die Schleimbeutelbildung darstellen, so können wir dem im Hinblick darauf vollkommen beipflichten, daß durch diese Ursachen im subeutanen Bindegewebe Gewebsflüssigkeit austritt, und zwar in einen wenn auch nur die Größe einer Gewebsmasche übertreffenden Gewebsspalt.

Ebenso wie der Sitz ist allen auch der Flüssigkeitserguß gemeinsam. Wir wissen gleichfalls aus anderen Beispielen, wie z. B. der Cysten- 
bildung nach größeren Blutergüssen (Rammstedt, Schulz, Berndt), daß Flüssigkeiten nicht organisiert werden, sondern daß das Gewebe eine Kapsel um sie herum bildet, die wiederum genau den Aufbau und die Auskleidung wie unsere Fälle besitzt. Ich habe einen ebensolchen Fall (Regeneration der Facsie, Lgb. Arch. Bd. 111) beschrieben, in dem nach Defektbildung im Unterhautzellgewebe und Füllung des Defektes mit einem Blutgerinnsel eine Spaltbildung auftrat, und auch dort dafür eine entsprechende Erklärung gegeben.

Auch A. Bier beschreibt in seinen Abhandlungen über Regeneration beim Menschen zwei Höhler bildungen nach Blutergüssen ${ }^{1}$ ). Die histologische Untersuchung der Wände dieser Fälle ergab die gleichen Bilder, wie die unsrigen. Demnach muß der Satz aufgestellt werden, daß Flüssigkeiten nicht organisiert werden, sondern daß um sie herum eine Membran gebildet wird, die, im wesentlichen bei Blut- oder Lymphergüssen gleich, im einzelnen nur quantitativeVerschiedenheiten aufweist.

Dort, wo die Innenwand ohne jede Membran im Sinne Heineckes geblieben ist, hat bei der Entstehung eine wesentliche Reizung keine Rolle gespielt. So ist die beschriebene Bursa praepatellaris entstanden. Durch eine abscherende Gewalt ist ein Gewebsdefekt mit Zerreißung der Lymphgefäße und breiter Erweiterung der physiologischen Lymphspalten verursacht worden. Es ist ein $\mathrm{Erguß}$ von Gewebsflïssigkeit entstanden, der nicht organisiert wird, sondern der sogar für die Erhaltung des Spaltes sorgt. Ein Vergleich mit der Synovia der Gelenke liegt hierbei nahe, da ja in dem Inhalt der operativ entstandenen Höhlen (Beobachtung 8 und 9) Synovin chemisch einwandsfrei festgestellt wurde. Die Synovia wiederum ist nicht nur das die Gleitfähigkeit erhaltende Moment, sondern sie erhält auch den Gelenkspalt (A. Bier).

Um diesen Spalt, der beim Schleimbeutel nicht von vornherein in voller Ausdehnung entstehen muß, bildet sich eine Auskleidung, wie sie sich um alle ähnlichen Ergüsse herum bildet. Die vielfach zu findenden Balken und Vorsprünge der Schleimbeutel sind Gewebsstränge, die vermöge größerer Festigkeit der abscherenden Gewalt mehr Widerstand leisten konnten als die Umgebung. Sie sind verdickt durch die Bildung der einhüllenden Membran, welche von der Wand auf sie übergeht.

Die Hygrome und Ganglien sind die gleichen Bildungen wie die Schleimbeutel. Das ist als Gemeingut der Literatur zu betrachten. Virchow nennt sie irritative Bildungen. Sie sind durch chronischtraumatische, entzündliche Reizungen entstanden. Das drückt sich auch in dem größeren Zellreichtum und in der derben Beschaffenheit der bindegewebigen Wand aus. Wir finden bei beiden den flüssigen Inhalt durch eine ein- oder mehrschichtige Lage von deckenden, gequollenen Bindegewebszellen abgeschlossen. Je geringer der Reiz, desto schwächer

${ }^{1}$ D Dtsch. med. Wochenschr. 1917 und 1918, IV. und XVIII. Abhandlung. 
und weicher ist die Bindegewebsmembran. Dies beweist das Präparat der 7. Beobachtung, von dem einzelne Stellen sehr an den Aufbau der Membrana synovialis erinnern. Auch in der Beobachtung 4 (Lympherguß), bei welcher der Inhalt einen wesentlichen Reiz nicht mehr ausgeübt hat, sehen wir einen dem Schleimbeutel fast gleichen Aufbau seiner Auskleidung.

Die Angabe Payrs, daß an der inneren Zone der Wand Capillaren spärlich sind, können wir bestätigen. Es fiel auf, daß die größeren Gefäße scheinbar in einem gewissen Abstand von der Innenfläche verlaufen und dort in Bündeln zusammenliegen, während Capillaren kaum weiter . nach der Oberfläche gefunden wurden. Stellenweise hatte die innerste Zone ein gequollenes, hyalin gewordenes Aussehen. Die Zellen in ihr schienen Kapseln um sich zu haben, so daß sie den Eindruck von Knorpelzellen machten. Dies entspricht der Angabe Stöhrs, daß die Zellen. mancher Schleimbeutel an der Innenfläche knorpelähnlich aussehen.

Die von A. Bier angegebene Füllung von Gewebsdefekten mit physiologischer NaCl-Lösung hat dahin geführt, daß es gelungen ist, den Schleimbeuteln und bekannten pathologischen Spalten und Cysten (Hygrom, Ganglion und Lympherguß) gleiche Höhenbildungen experimentell herzustellen. Wir sind so in die Lage versetzt, den ersten Bildungsvorgang dieser Erscheinungen genauer festzulegen. Er besteht, entgegen der bisherigen Annahme, nicht in einer Bindegewebsverflüssigung, sondern in der primären Entstehung einer Höhle, in welche hinein ein mehr oder weniger ausgedehnter Erguß von Gewebsflüssigkeit stattfindet. Die Gewebsflüssigkeit entstammt den bei diesem Vorgang in großer Zahl eröffneten Lymphgefäßen und -spalten. Daher gehört auch ein großer Teil der Wandung solcher Hohlräume dem Lymphgefäß führenden, ausgedehnte Lymphspalten enthaltenden subcutanen Gewebe oder den Zwischengeweben an. In dem flüssigen Inhalt ist mehrfach Synovin nachgewiesen worden, daraus erklärt sich, daß mehrfach Bilder entstehen, die auf einen Auflösungsprozeß der obersten Gewebsschichten hindeuten. Durch diesen Vorgang wird erklärlich, daß selbst enge Gewebsspalten nicht verkleben, sondern erhalten bleiben. Bleibt der Vorgang der Höhlenbildung - ich begreife darunter auch diejenigen Ereignisse, bei denen durch Zerreißen von Bindegewebssträngen zum Beispiel mehrere physiologische Lymphräume zu einer Höhle vereinigt werden - ohne jede Einwirkung eines Reizes, so tritt in dem die Wandung bildenden Bindegewebe höchstens eine Quellung der Bindegewebsfasern auf, ohne jede Zellwucherung. Macht sich aber irgendein Reiz geltend, so wird aus der entzündlichen Charakter annehmenden Gewebsflüssigkeit ein fibrinhaltiger Niederschlag ausgeschieden, der auf der Wand oder an irgendwelchen, in der Höhle liegenden oder sie durchquerenden Bindegewebsbestandteilen abgesetzt und organisiert wird. 
Die nunmehr, je nach der Intensität des Reizes zahlreichen, einwandernden Zellen des Granulationsgewebes organisieren diesen Niederschlag nicht geichmäßig, sondern lassen Inseln und Streifen in der Tiefe zurück, die erst später resorbiert und ersetzt werden. In solchen, unter Reizwirkung stehenden Fällen bildet sich auch ein mehr oder weniger massiger Abschluß des Gewebes gegen den Inhalt. Das Streben nach einem solchen muß sehr intensiv sein, da sich aus den mikroskopischen Bildern ersehen läßt, wie frühzeitig eine deckende Zellschicht auftritt.

Für die primäre Höhlenbildung halten wir eine chronisch-traumatische Entzündung als ätiologisches Moment für wahrscheinlich. Durch die Entzündung werden die sonst elastischen, bieg- und zugfesten Bestandteile des lockeren Bindegewebes in dieser Eigenschaft geschädigt. Wenn das Bindegewebe aber seine Elastizität verliert, kann es leicht zerrissen werden. Auf diese Weise läßt sich die Entstehung der primären Hohlräume erklären, in die dann ein Erguß von Gewebsflüssigkeit stattfindet.

\section{Literaturverzeichnis.}

Ledderhose, V., Dtsch. Zeitschr. f. Chir. 3y. - Schuchardt, Virchows Archiv 121. - Falks on, Arch. f. klin. Chir. 32. - Thorn, Arch. f. klin. Chir. 52. - Ri ts chl, A., Bruns Beiträge 14. - Sch ulz, F., Bruns Beiträge 33. - Wolter, Dtsch. Zeitschr. f. Chir. 64. - Ricker, Virchows Archiv 163. - Rammstedt, Arch. f. klin. Chir. 61. - Sumita, Arch. f. klin. Chir. 99. - Berndt, Arch. f. klin. Chir. 65. - Virchow, Die krankh. Geschwülste, Berlin 1863. - Volkmann, R., Dtsch. Zeitschr. f. Chir. 41. - Payr, Dtsch. Zeitschr. f. Chir. 49. Langemack, Arch. f. klin. Chir. 70. - Graf Haller, Virchows Archiv 224. Staehli, Inaug.-Diss. Würzburg 1889. - Hei necke, W., Erlangen 1868. - Stöhr, Lehrbuch d. Histologie, 10. Aufl. - Bier, A, Beobachtungen über Regeneration usw., Dtsch. med. Wochenschr. 1917/18. - Lubosch, W., Jena 1910. - Gussenbauer, zitiert nach Wolter.

\section{Tafelerklärung.}

Abb. 1. Beob. 5. Färbung nach v. Gieson. Stück aus der Wand des 10 Tage alten Hohlraumes. Vergrößerung ca. 50fach. $a$ Niederschlag. $b$ Deckende Zellschicht. $g$ Junges Granulationsgewebe, welches den Niederschlag organisiert. $n$ Rest des Niederschlages im jungen Granulationsgewebe. (Linie zeigt auf die gelbe umschriebene Stelle.) $m$ Muskulatur.

Abb. 2. Beob. 6. Färbung nach v. Gies on. Stück aus der Wand des 15 Tage alten Hohlraumes. Vergrößerung 345fach. a Innere Begrenzung der Wand. $n$ Niederschlag in Organisation. $m$ Niederschlag in der Tiefe des jungen Granulationsgewebes.

Abb. 3. Beob. 7. Färbung nach v. Gieson. Stück aus der Wand des 19 Tage alten Spaltes. Vergrößerung 540fach. a Deckende Zellschicht. $n$ Fädige Reste des Niederschlages. $m$ Lockeres junges Bindegewebe. 
रूड
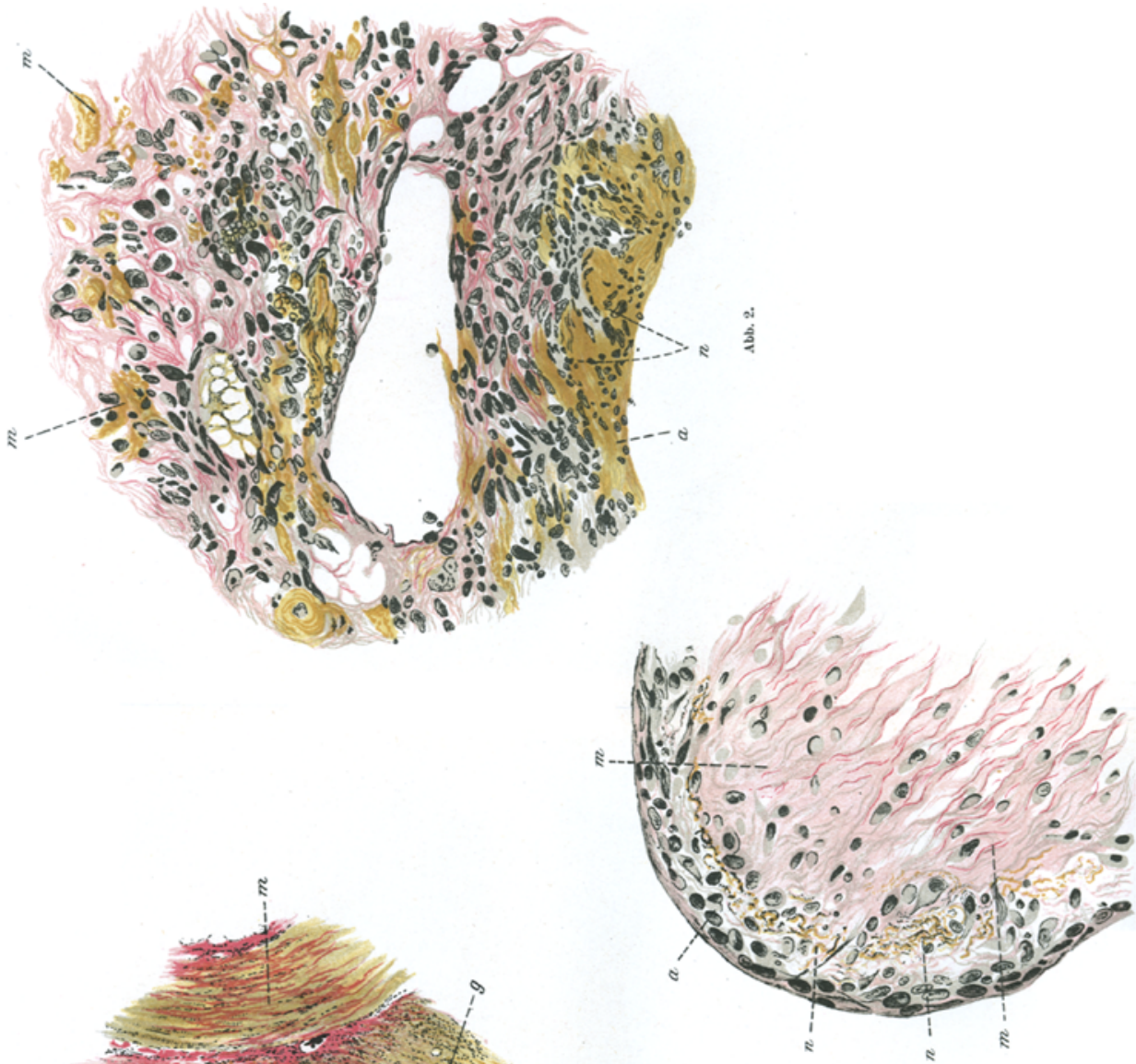

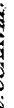

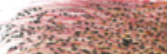

60
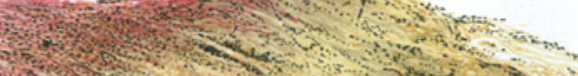

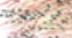

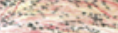

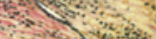
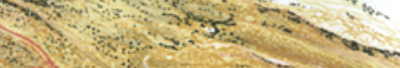

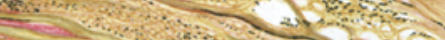

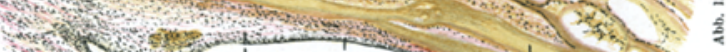

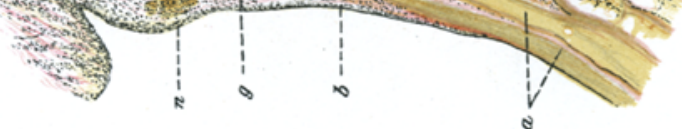

